\title{
Acompañar, integrar y discernir
}

\author{
Juan de Dios Larrú \\ Universidad San Dámaso - Madrid
}

\begin{abstract}
Resumen: El presente estudio se propone iluminar la recepción de la exhortación apostólica Amorislaetitia. Para ello se toma como hilo conductor los tres verbos que aparecen en el capítulo VIII de la misma: acompañar, integrar y discernir, teniendo presente el conjunto de la exhortación.Siguiendo de cerca el vademécum escrito por tres profesores de la sede central del Instituto Teológico Juan Pablo II, consideramos sucesivamente el significado del acompañamiento, la integración y el discernimiento para la pastoral familiar. En el acompañar nos detenemos en el acompañamiento de novios en su preparación próxima, en el acompañamiento de los primeros años de matrimonio, y en el acompañamiento de situaciones difíciles, como tres aspectos singularmente importantes hoy. El retorno a la comunión plena en la Iglesia es el objetivo del camino de la integración que tiene como sujeto a la entera comunidad cristiana. Finalmente, discernir no quiere decir discernir sobre el estado de gracia de una persona, cosa que únicamente le corresponde a Dios, sino que el objeto del discernimiento es triple: el deseo, el vínculo matrimonial y los pasos concretos.
\end{abstract}

\begin{abstract}
This paper pretends to highlight certain aspects of the Apostolic Letter AmorisLaetitia. For doing so, we use three verbs that appear in its chapter VIII as drivers: To go with, to integrate and to discern. Following the vade mecum written by three professors in the central see of Theological Institute John Paul II, we study the meaning of accompanying, integration and judgment for the Family Pastoral. First at all, we focus on accompanying fiancés as they are preparing their wedding, during the first years of marrying and during difficult times, as three important issues nowadays. Regarding the integration, the comeback to the full communion in the Church is the target of this action that involves the whole Christian community. Finally, to discern does not mean to judge the status of gratia of the human being -as it is responsibility of God, but to discern includes three goals: the desire, the marital tie and the specific steps to be given.
\end{abstract}

\section{INTRODUCCIÓN}

El objetivo principal de este trabajo es buscar la mayor claridad posible a la hora de interpretar adecuadamente la exhortación post-sinodal Amoris laetitia en su conjunto. La recepción del documento y las diferentes interpretaciones del 
mismo han abierto un debate teológico que en no pocas ocasiones ha sido áspero y duro ${ }^{1}$. En él han de buscarse las razones reales para una mejor comprensión del misterio y la necesidad de vivir la verdad recibida de Cristo. Tomamos como inspiración fundamental elVademécum editado por tres profesores de la sección central del Instituto Juan Pablo $\mathrm{II}^{2}$. La clave de lectura fundamental es la fidelidad al Evangelio del matrimonio y la familia.

Para leer de modo coherente la exhortación hemos de tener en cuenta tres criterios básicos. En primer lugar, la coherencia con el itinerario sinodal en el que se inserta y enmarca el documento. En este sentido, es necesario constatar cómo los dos documentos más citados son respectivamente los textos conclusivos de los sínodos de 2014 y 2015, denominados Relatio synodi (18-10-2014) y Relatio finalis (24-10-2015) ${ }^{4}$. En segundo lugar, la coherencia interna del documento leído en su totalidad, que coloca en el centro del misterio de la familia, el amor, abordado en los capítulos cuarto y quinto de la exhortación. En último lugar, el tercer criterio hermenéutico es la tradición de la Iglesia en continuidad con el Magisterio precedente. En este sentido, conviene recordar que la enseñanza magisterial en la Iglesia se ha de interpretar desde la lógica de la continuidad y no de la ruptura ${ }^{5}$. En esta perspectiva, conviene recordar que la doctrina y la pastoral van inseparablemente unidas. De hecho, en el tercer capítulo de Amoris laetitia se hace un repaso de los principales documentos de la Iglesia sobre el matrimonio y la familia desde la constitución pastoral Gaudium et spes del Concilio Vaticano II hasta nuestros días.

Los tres criterios mencionados convergen en lo que podríamos denominar la clave fundamental de interpretación de la pastoral familiar: el amor verdadero. A semejanza del relato del encuentro entre Jesús y la samaritana (Jn 4) que menciona la exhortación, el deseo del amor verdadero ha de guiar toda la acción pastoral de la Iglesia, a imitación de Cristo que"dirigió una palabra a su deseo de amor verdadero, para liberarla de todo lo que oscurecía su vida y conducirla a la alegría plena del Evangelio" (AL 294). De este criterio fundamental se siguen dos importantes consecuencias: la primera es que la pastoral familiar mira el vínculo conyugal como primera expresión de la verdadera misericordia divina. En efecto desde la lógica interna del amor, se ha de promover lo que la exhortación denomina"pastoral del vínculo"6. De este modo, se concreta la estrecha relación entre misericordia y verdad, entre misericordia y alianza. La medida de la alianza conyugal no es la debilidad humana sino la gran misericordia de Dios.

Sobre este debate, puede verse: J. GRANADOs, “Tres lecturas de Amoris laetitia, y una cuarta. Nota sobre el debate en torno a la Exhortación apostólica", Anthropotes 33 (2017) 449-468.

2 J. Granados-S. Kampowski-J.J. Pérez-Soba, Acompañar, discernir, integrar. Vademécum para una nueva pastoral familiar a parir de la exhortación Amoris laetitia, Fonte, Burgos 2017.

Citada 51 veces de modo explícito en pie de nota.

Citada 82 veces en notas a pie de página.

BENEDICTO XVI, Discurso a la curia romana, (22-12-2005).

6 Francisco, Amoris laetitia, n. 102. 
La indisolubilidad matrimonial no es un yugo pesado, sino un don de Dios que los cónyuges han de aprender a recibir en la fidelidad a un amor de Cristo que les une y vincula dinámicamente. La segunda consecuencia es que en los casos difíciles en los que sea preciso un camino de conversión, este proceso tendrá siempre como luz la verdad del amor y del vínculo. Con los verbos acompañar, discernir e integrar la fragilidad se indica el modo como la Iglesia, siguiendo la mirada de Cristo, desea acercarse a las personas que sufren heridas y viven situaciones bien dolorosas.

\section{EL ARTE DEL ACOMPAÑAMIENTO}

La primera parte del vademécum explica el significado del acompañamiento. La etimología del verbo acompañar está relacionada con la acción de compartir el pancon otros (cum panibus). La exhortación, de un modo muy realista, constata en primer lugar una carencia efectivo del mismo. Por consiguiente, plantear una pastoral de acompañamiento supone una fuerte conversión. El hombre contemporáneo se caracteriza por ser un solitario interconectado. $\mathrm{Mu}$ chas familias no reconocen en la Iglesia una capacidad de ayuda en los momentos difíciles y se sienten solas. Es preciso, pues, combatir la soledad, saliendo al encuentro de los matrimonios y las familias. Conviene notar además que no basta querer acompañar, sino que es preciso saber hacerlo.

Es necesario, por consiguiente, formar personas, matrimonios y familias que aprendan a acompañar a otras. El acompañamiento cristiano requiere virtudes como la escucha paciente, la palabra y el gesto oportunos, saber adaptarse a los tiempos de Dios, la fortaleza de no perder la esperanza... Ya vemos que no consiste en una estrategia, sino en un verdadero arte. La acogida es el primer momento del acompañamiento que implica aprender a generar un clima de confianza donde las personas puedan abrirse al diálogo. El acompañamiento personal y concreto es inseparable del realismo de la vida de las familias ${ }^{7}$.

Jesucristo es el Maestro que nos enseña el arte del acompañamiento. Es significativa al respecto la escena de Emaús (Lc 24,13-35), en la que brilla la figura de Cristo, como aquel que ofrece una luz en el camino. A la luz de Cristo, la palabra de Dios y los sacramentos son las referencias fundamentales para el acompañamiento. De este modo, acompañar es un modo de anunciar el Evangelio unido estrechamente al seguimiento de Cristo. Este fundamento cristológico del acompañamiento implica promover con prácticas concretas la amistad con Cristo de cada persona, matrimonio y familia.

La familia es el primer lugar de acompañamiento. En este sentido, no son los sacerdotes los únicos que acompañan a las familias, sino que las familias

J.J. PÉREZ-SoBA, “La familia, el lugar donde la realidad habla: un principio pastoral”, Anthropotes 30 (2014) 691-718. 
tienen la misión de acompañar a otras familias. Todas las familias tienen necesidad de ser acogidas y acompañadas en su propio camino existencial. El amor verdadero es el hilo conductor de todo acompañamiento. La paciencia es una virtud propia de este proceso $^{8}$. Esta virtud contiene un particular nexo con la temporalidad. Es preciso caer en la cuenta que vivimos inmersos en una profunda crisis del tiempo, que se ha fragmentado en instantes efímeros y fugaces. La disincronía genera dispersión temporal donde no existe ritmo ni rumbo que de sentido y significado a la vida ${ }^{9}$. En tal sentido, se verifica un nexo entre la ignorancia del pasado, la concentración exclusiva en el instante fugaz y la incapacidad de imaginar el futuro. La impaciencia y la duración vacía tienen el mismo origen. Se trata, muchas veces, de sembrar una pequeña semilla para que pueda ir, poco a poco, creciendo.

La gradualidad es la ley pedagógica del acompañamiento y del seguimiento de Cristo. Caminar detrás de Él, seguir sus pasos, es oportunidad de crecimiento. Siempre se puede crecer en el bien, y aún los pequeños pasos en este itinerario de crecimiento tienen un particular valor. Junto a ello, es necesario recordar que entre el bien y el mal moral no hay término medio. En este sentido, hay que rechazar con vigor la gradualidad de la ley moral. Ya en el sínodo de la familia de 1980 se usó el término gradualidad, como se refleja en varios textos relacionados con aquel sínodo, y como refleja Familiaris consortioen los nn. 9,33 y $34^{10}$. Si se identifica la gradualidad de la ley con la ley de la gradualidad, se concluye en un dualismo que mantiene en teoría los principios, pero que los adapta en la práctica a las situaciones de hecho según las posibilidades de cada uno. Desde el realismo de la gracia, la negación de la gradualidad de la ley es la primera condición para que se verifique una verdadera pedagogía de la gradualidad ${ }^{11}$. En este sentido, conviene recordar que el objetivo es siempre la santidad a la que estamos llamados todos los cristianos (LG 40).

En el evento de la conversión conviene distinguir dos niveles:

a) Hay un momento de conversión inicial. Es la acogida de la caridad, que comporta el rechazo radical y total del pecado. La vida cristiana se inicia por un don de la gracia que provoca la conversión fundamental, que no conoce componendas con todo aquello que se opone a Dios. En este nivel no puede haber grados: se trata de la dimensión absoluta del don de la conversión. Hablando con propiedad no se trata ni siquiera de una primera

8 G. Angelini, Le virtù e la fede, Glossa, Milano 1994, 126-169.

9 Cf. Buyng-Chul Han, El aroma del tiempo. Un ensayo filosófico sobre el arte de demorarse, Herder, Barcelona 2015.

10 J.-M. LustigeR, “Conversione e gradualità”, en AA.Vv, LA «Familiaris consortio», Libreria Editrice Vaticana, Città del Vaticano1982, 31-57.

11 Cf. O. Gotia, "Gradualità e conversione", en: J.J. Pérez-SobA-J. DE LA Torre (a cura di), Il primato del Vangelo e il luogo della morale: gerarchia e unità nella proposta cristiana, (Atti del XV Colloquio di Teologia Morale, 21-22 novembre 2014, Roma), Cantagalli, Siena 2016, 209-226. 
etapa, sino de la condición previa del camino. Se pide el reconocimiento honesto y claro de la verdad: llamar las cosas por su nombre (decir bien al bien y mal al mal) y arrepentirse del pecado confiándose en la misericordia.

b) Luego viene el crecimiento en la caridad, a través de la consolidación y el perfeccionamiento de la propia respuesta positiva hacia Dios. Ésta no sucede por añadidura de algo que falta, sino por intensificación, por incremento orgánico interno de todo aquello que se nos ha dado desde el inicio. En este nivel se verifica un camino gradual de conversión en la tensión permanente hacia la santidad.

\subsection{El acompañamiento en la preparación al matrimonio}

La exhortación apostólica anima a superar la concepción de un requisito de preparación sacramental, reducido a momentos muy determinados, y en ocasiones marginales, para situarlo dentro de la pastoral de la Iglesia como conjunto. Se trata de comprender que acompañar el camino de amor de los novios es un bien para toda la comunidad cristiana.

La pastoral prematrimonial está llamada a superar la idea de una catequesis clásica para convertirse en efectivo acompañamiento de novios que permita un proceso de maduración en el amor verdadero. De este modo, se puede dilatar la distensión temporal, desde la preparación inmediata a la preparación próxima y remota (FC 66). Amoris laetitia habla de dos niveles de preparación al matrimonio: uno genérico, que se dirige a todos los jóvenes para aprender a amar; otro específico, para los que de hecho han formalizado un noviazgo. Entre ambos niveles es preciso establecer prácticas de transición adecuadas. Las prácticas propias del noviazgo son acciones comunes que implican a los novios, pero que afectan también a la sociedad y a la Iglesia, y han de ir configurando un verdadero camino que abarque la totalidad de la vida ${ }^{12}$. Es necesario elaborar propuestas de itinerarios para novios que les permitan madurar y verificar su vocación al amor ${ }^{13}$. Esto supone que entre la pastoral juvenil y la pastoral matrimonial exista una profunda reciprocidad y comunicación positiva.

Los programas específicos de educación de la afectividad y la sexualidad no han de reducirse a unas charlas informativas, sino que han de conformar el corazón de las personas y sus acciones ${ }^{14}$. En estrecha colaboración con los padres, con personas bien formadas, estos programas han de impartirse en las escuelas, parroquias, movimientos y asociaciones de modo sistemático y progresivo.

12 J. NoRIEGA, "La preparación al matrimonio en el noviazgo con prácticas propias", en J. LARRÚ (ed), La grandeza del amor humano, BAC, Madrid 2016, 311-321.

13 J. NoRIEGA, "Acompañar el camino del amor: la propuesta de un itinerario para novios", Anthropotes 32 (2016) 81-106.

14 En España se han ido implantando diversos programas en las últimas décadas: Teen Star, Aprendamos a amar, Sabe, ... y se han formado muchas personas en este campo, aunque todavía queda mucho por hacer. 
El acompañamiento en el noviazgo adquiere un valor singular. En lugar de ver el tiempo como enemigo del amor, se trata de verlo como un paso de Dios que en la gracia hace madurar.

\subsection{El acompañamiento de los primeros años de matrimonio ${ }^{15}$}

El sacramento del matrimonio no es el final de un camino, sino más bien el inicio de una realidad nueva, que es preciso edificar cada día. La experiencia revela que los primeros años de matrimonio son de una importancia pastoral vital. En ellos se ponen las bases y los cimientos de la familia, y no es tiempo fácil por la multiplicidad de sus exigencias. Según afirman las estadísticas, en los siete primeros años se producen más del 60\% de las separaciones. Llama poderosamente la atención la ausencia de atención a los matrimonios y las familias en estos años tan importantes para ellos.

Se ha de superar decididamente el esquema de considerar los sacramentos como un final de etapa, que provoca después que las personas queden aisladas y sin referencias claras y concretas. Para ello es muy importante contar con una red adecuada de grupos de matrimonios en las parroquias, asociaciones y movimientos. Es conveniente aprovechar lo que la exhortación denomina"espacios de acompañamiento" (sacramentos [bodas, bautizos, comuniones, funerales], bendición de la casa, visitas...), jornadas parroquiales de la familia, expresiones de religiosidad popular. Se trata de ir configurando un modelo de parroquia "amiga de la familia".

\subsection{El acompañamiento en casos difíciles}

Cuando se da una debilidad mayor, el acompañamiento ha de ser espe$\mathrm{cial}^{16}$. Es necesario tener en cuenta la necesidad y debilidad real de las personas. En primer lugar, antes que la irregularidad, conviene tener en cuenta la dificultad de las personas para afrontar su vida cristiana. En una situación de sufrimiento, la primera atención ha de dirigirse a promover la presencia cercana de Cristo. También en estos casos, el acompañamiento de otros matrimonios es muy importante.

En el drama de las separaciones, es necesario animar a las personas que no se han vuelto a casar a buscar un acompañamiento adecuado ${ }^{17}$. En general se llega a muy pocas de estas personas que viven su ruptura en la soledad y el dolor de las familias, pero sin la cercanía de la comunidad. Las mayores víctimas de la

15 L. Melina (a cura di), I primi anni di matrimonio. La sfida pastorale di un periodo bello e difficile, Cantagalli, Siena 2014.

16 Cf. J.J. Pérez-SobA, "Saber acompañar con pasos de salvación: cómo afrontar las "situaciones complejas"", Anthropotes 31 (2015) 409-437.

17 E. ScotTi, La fidelidad que escribe la historia, Monte Carmelo, Burgos 2015. 
separación son los hijos que generalmente viven un grave trauma y no reciben la ayuda adecuada por parte de la Iglesia. Ese es un campo específico que ha de estar presente en los Centros de Orientación Familiar, y a su nivel en la parroquias y en los colegios.

Las familias monoparentales han de ser también objeto de la maternidad de la Iglesia. Con delicadeza y cercanía, es preciso acompañar estas situaciones dolorosas, a veces ya desde el embarazo.

Una ayuda especial ha de ofrecerse a las personas que han abortado. En muchas ocasiones es preciso apoyarlos para superar el "síndrome post-aborto" con todo lo que supone de ruptura psíquica, personal, espiritual y de relaciones humanas.

En las situaciones irregulares se han de preparar procesos bien determinados, al menos a nivel diocesano, con personas, consagrados y matrimonios especialmente preparados. De este modo se ofrece unidad, criterios comunes, evitando al dispersión y la ambigüedad en el modo de comprender este acompañamiento. En estos casos, es preciso evitar tanto la arbitrariedad como la rigidez.

Para los divorciados vueltos a casar, se puede elaborar un itinerario de crecimiento personal con diversos pasos en el que el tiempo y el diálogo son fundamentales. El itinerario habrá de constar de tres pasos fundamentales:

- Acogida evangélica de las personas, que no son vistas como un caso, sino dentro de un marco de integración. En no pocas ocasiones es posible acercarse a estas personas a través de los hijos. Acoger es iniciar un camino y no aceptar hechos consumados. Una vez hecha la acogida, el pastor se podrá formar un juicio primero de la situación.

- Anuncio de la verdad del Evangelio como luz en sus vidas. El modelo será el de una nueva iniciación cristiana. Esta iniciación consistirá, por un lado, en la participación en un catecumenado de adultos con el fin de comprender las claves básicas de la vida cristiana, y en segundo lugar que comprendan su situación respecto al Evangelio del matrimonio y la familia, penetrando en el sentido del vínculo indisoluble como expresión del ser una sola carne.

En paralelo con el ritual de iniciación cristiana de adultos, se incluirán pasos rituales que fomenten un mayor compromiso personal dentro de este camino. Los signos visibles son importantes para reforzar el sentido de pertenencia.

- El tercer paso es enfrentarles con su propia verdad, para ver qué obstáculos existen ante las exigencias del seguimiento de Cristo. Entrar en un camino de conversión singular, cuyo horizonte será la recepción del sacramento de la penitencia y de la Eucaristía, bajo las debidas condiciones. La admisión es personal aunque sea muy conveniente que el matrimonio en cuanto tal se implique en este proceso. La cuestión del perdón es el centro vital del entero proceso de iluminación. 


\section{INTEGRAR: EL RETORNO A UNA COMUNIÓN PLENA}

La decisión de vivir de modo contrario al vínculo conyugal siempre es reversible con la gracia de Dios. La parábola del hijo pródigo (Lc 15,11-32) nos habla de este itinerario de integración hacia la casa del Padre. La meta del camino de conversión es siempre poder vivir la vida plena de Jesús ${ }^{18}$.

Las personas divorciadas en nueva unión son bautizados, hermanos y hermanas nuestras, que acarrean consigo una gran sufrimiento. No existe ninguna excomunión canónica que les impida participar en la vida ordinaria de la Iglesia. Podemos preguntarnos entonces qué significa que hay que integrarlos. Es importante recordar que a la Iglesia no se pertenece únicamente por un nexo invisible, sino que hay criterios de incorporación visible, pues la Iglesia nace de la Encarnación que afecta a toda la persona.

Los criterios de pertenencia visible son principalmente tres: confesar y vivir la fe de la Iglesia, estar en comunión con el cuerpo de la Iglesia, bajo los pastores; llevar una vida en armonía con los sacramentos. Estos criterios se armonizan en la caridad. El tercer criterio es la principal dificultad que hay que curar en estos fieles que tiene relación con el primer criterio también pues la coherencia de la vida sacramental se encuentra en estrecha relación con la vida de fe.

En el camino de integración en la vida plena de la Iglesia, es necesario tener cuidado para no confundir la integración con una mera inclusión social. En la inclusión se trata de eliminar las barreras que se han creado por injusticias y desigualdades. La lógica de la participación plena en la Iglesia es diferente pues consiste en formar parte de una comunión en que se comparte la misma vida, acogiendo el don originario de Dios. El proceso de integración ha de dirigirse a sanar la herida.

La causa de la falta de pertenencia no es el fracaso del primer matrimonio, sino que la verdadera enfermedad es la segunda unión que han establecido. Mientras vivan en contra del vínculo matrimonial, su existencia estará fragmentada. Ciertamente estas personas necesitan de una cercanía y de un acompañamiento misericordioso, pero es importante evitar equívocos con respecto a la genuina misericordia. Ésta no se reduce a la simple compasión emotiva, ni tampoco es la tolerancia. La verdadera misericordia no solamente compadece, sino que sana, no solamente tolera, sino que transforma.

La mayor miseria que padece el hombre es el alejamiento de Dios, la pérdida de la grandeza de la vida que el Padre nos ha prometido en Jesús. Como enseñó el Concilio de Trento, cuando uno es consciente de haber cometido un pecado mortal, ha de confesarse antes de recibir la Eucaristía. Hay algunos pecados que son manifiestos, tocan a las relaciones visibles, al cuerpo social de la Iglesia. Es necesario, por tanto, no solamente discernir el espíritu sino también discernir el cuerpo, es decir, el modo concreto en que vivimos las relaciones.

18 Cf. J. Larrú (ed), El camino de la misericordia, Universidad San Dámaso, Madrid 2017. 
La integración de la que estamos hablando es sacramental, pues los sacramentos tocan nuestro cuerpo, nuestra situación concreta en la carne ${ }^{19}$. Son situaciones objetivas que han de ser transformadas con paciencia. Dios sigue actuando, pero mientras el terreno no sea el adecuado, la semilla no podrá germinar y arraigarse para dar fruto. Hemos de tener en cuenta que la acción de la gracia sigue la lógica de la Encarnación. Dado que el camino es sacramental, es Dios quien lo inicia y lo mueve. Se realiza con toda nuestra fragilidad, pero con toda la esperanza puesta en la acción de Dios.

El camino pasa primero por el sacramento de la Penitencia, para después, conducir a la Eucaristía. No es preciso preocuparse excesivamente por los tiempos. En la confesión el penitente pone su historia junto a la historia de Jesús que me ha amado y se ha entregado a la muerte por mí (Ga 2,20). Para poder absolver el confesor tiene que verificar que la persona está dispuesta a salir de su situación, a abandonar los cimientos sobre arena movediza e implantarse en la roca.

No se trata de discernir su culpabilidad subjetiva, sino de discernir si quiere aceptar la forma objetiva de vida de Jesús (corporal, sacramental). Conceder la absolución antes de tiempo dañaría al penitente, y un daño al bien común de la Iglesia, siguiendo una lógica de tolerancia y de gradualidad de la ley. Quien sigue su conciencia invenciblemente errónea no peca, pero esto no significa que su acción sea buena, ni que no haga daño. Es esencial hacer lo posible por ayudar a la persona a salir de esta tiniebla. El foro sacramental no se puede identificar con la conciencia errónea.

Para comer el cuerpo de Jesús, hay que estar dispuesto a comer las palabras de Jesús. Santo Tomás decía que la si la Iglesia administrara el sacramento a alguien que no está preparado para recibirlo, sería como imponerle violencia: forzar sobre él un modo de vida que aún no quiere acoger cordialmente.

El catecumenado antiguo contenía el signo de la sal como camino hacia la Eucaristía. La sal indicaba el deseo de comida, el gusto anticipado de lo que será el banquete eucarístico. En este sentido es bueno proponer la práctica de la comunión espiritual. El deseo de comunión y el deseo de conversión del corazón han de ser armonizados, pues el sacramento toca la carne y tiende a informar todas nuestras relaciones.

Las notas 336 y 351 no suponen un cambio en la disciplina eucarística. Las normas a las que se refiere la nota 336 se refieren al contexto de AL 299, elección de padrinos o madrinas, oficios de lector y acólito, normas referentes a la integración en la Iglesia. Se mantiene, por tanto, que sí hay normas que valen para todos en materia sacramental.

La nota 351 es muy general, y se refiere genéricamente a las condiciones objetivas de pecado, sin indicar que estas sean manifiestas, ni que la persona se obstine en permanecer en ellas, ni en oposición directa a un sacramento.

19 J. Granados, Tratado general de los sacramentos, BAC, Madrid 2017. 
El caso de los divorciados"vueltos a casar"es del todo específico, porque en él se vive en contra de la realidad de un sacramento. Razones de lógica interna sacramental hacen imposible que quiera efectivamente recibir un sacramento quien vive en modo contrario a otro sacramento.

Es importante, al respecto, tener en cuenta lo que afirma Melina: "La tragedia en la que viven estas personas no se puede valorar desde el sentimiento ni desde la facticidad concreta. El adulterio no es únicamente un pecado contra la intimidad conyugal; es principalmente un pecado contra la fidelidad de Dios, contra lo que Él ha unido. Para poder recibir la absolución sacramental es necesario que exista el propósito de no volver a cometer el pecado que se confiesa. La confesión no puede ser la autorización a continuar en una situación que es objetivamente contraria al matrimonio. El acto sexual realizado fuera del matrimonio es o adulterio o fornicación" ${ }^{\prime 2}$.

No se trata, por consiguiente, de nuevas normas, sino de la necesidad de una conversión pastoral. Las vías no las abre un texto, sino el esfuerzo común por acercarse a estos hermanos y acompañarles en el camino hacia Cristo. La exhortación propone dos vías concretas:

a) comenzar un itinerario de reintegración plena en la Iglesia a las persona extraviadas, guiado por el obispo (AL 291.300).

b) anima a los confesores a que tengan en cuenta las situaciones atenuantes a la hora de verificar si una persona tiene el propósito de comenzar a vivir según el Evangelio en la lógica de los pequeños pasos de crecimiento según la ley de la gradualidad (AL 301-306).

Si la Eucaristía es una medicina contra el pecado, a veces, diferir la medicina, es un acto medicinal (San Buenaventura), porque hay medicinas que, tomadas antes de tiempo, hacen más mal que bien.

a) La imposibilidad de recibir la comunión les recuerda que hay un problema en el modo en que establecen y viven sus relaciones visibles. Siembre en ellos una inquietud.

b) Además han de pensar en el bien que hacen a otros cuando permanecen fieles a esta disciplina.

c) También para la educación de sus hijos en la fe.

d) Manteniendo esta disciplina mantienen viva su fe y se unen a toda la Iglesia para confesarla.

Ceder en este punto no sería como abrir una puerta en las paredes para que entrase más gente, sino abrir un boquete en el fondo del barco que se inundaría

20 L. Melina, “El sacerdote, médico que cura las heridas", en: C. Granados (ed), Sacerdotes, ¿con qué futuro?, BAC, Madrid 2017, 143-144. 
irremediablemente. No caer en la tentación de pensar que no es factible la conversión, pues es lo que pide el Evangelio (AL 102).

Es preciso recordar que el camino de integración lo realiza la entera comunidad cristiana. Esto es singularmente importante, pues las familias viven sin la ayuda de una sociedad que las apoye (AL 32). Esto es una gran mal para la familia, porque tantas veces la empuja a recluirse en relaciones-burbuja, como si fuera una isla, mientras ella tiene una vocación de apertura.

Para ser comunidad que integra, la Iglesia tiene que edificar una casa común de buenos cimientos en medio del desierto individualista de la sociedad contemporánea. Jesús en el Sermón del Monte enseña la parábola de la casa. La tenemos en dos versiones, Mateo(Mt 7, 24-29) y Lucas (Lc 6,47-49). En la primera se trata de dos tipos de terrenos, roca o arena; en la segunda, de dos profundidades de construcción, para llegar a la roca. Dos tipos de situación familiar.

\section{DISCERNIR: UN RECORRIDO A LA LUZ DE LA VERDAD}

El discernimiento forma parte del recorrido, no solo de la meta. Para comprender el significado del discernimiento el punto de partida es el texto de Familiaris consortio n. 84. Dice textualmente los siguiente:

"La experiencia diaria enseña, por desgracia, que quien ha recurrido al divorcio tiene normalmente la intención de pasar a una nueva unión, obviamente sin el rito religioso católico. Tratándose de una plaga que, como otras, invade cada vez más ampliamente incluso los ambientes católicos, el problema debe afrontarse con atención improrrogable. Los Padres Sinodales lo han estudiado expresamente. La Iglesia, en efecto, instituida para conducir a la salvación a todos los hombres, sobre todo a los bautizados, no puede abandonar a sí mismos a quienes —unidos ya con el vínculo matrimonial sacramental- han intentado pasar a nuevas nupcias. Por lo tanto procurará infatigablemente poner a su disposición los medios de salvación.

Los pastores, por amor a la verdad, están obligados a discernir bien las situaciones. En efecto, hay diferencia entre los que sinceramente se han esforzado por salvar el primer matrimonio y han sido abandonados del todo injustamente, y los que por culpa grave han destruido un matrimonio canónicamente válido. Finalmente están los que han contraído una segunda unión en vista a la educación de los hijos, y a veces están subjetivamente seguros en conciencia de que el precedente matrimonio, irreparablemente destruido, no había sido nunca válido.

En unión con el Sínodo exhorto vivamente a los pastores y a toda la comunidad de los fieles para que ayuden a los divorciados, procurando con solícita caridad que no se consideren separados de la Iglesia, pudiendo y aun debiendo, en cuanto bautizados, participar en su vida. Se les exhorte a escuchar la Palabra de Dios, a frecuentar el sacrificio de la Misa, a perseverar en la oración, a incrementar las obras de caridad y las iniciativas de la comunidad en favor de la justicia, a educar a los hijos en la fe cristiana, a cultivar el espíritu y las obras de 
penitencia para implorar de este modo, día a día, la gracia de Dios. La Iglesia rece por ellos, los anime, se presente como madre misericordiosa y así los sostenga en la fe y en la esperanza.

La Iglesia, no obstante, fundándose en la Sagrada Escritura reafirma su praxis de no admitir a la comunión eucarística a los divorciados que se casan otra vez. Son ellos los que no pueden ser admitidos, dado que su estado y situación de vida contradicen objetivamente la unión de amor entre Cristo y la Iglesia, significada y actualizada en la Eucaristía. Hay además otro motivo pastoral: si se admitieran estas personas a la Eucaristía, los fieles serían inducidos a error y confusión acerca de la doctrina de la Iglesia sobre la indisolubilidad del matrimonio.

La reconciliación en el sacramento de la penitencia — que les abriría el camino al sacramento eucarístico- puede darse únicamente a los que, arrepentidos de haber violado el signo de la Alianza y de la fidelidad a Cristo, están sinceramente dispuestos a una forma de vida que no contradiga la indisolubilidad del matrimonio. Esto lleva consigo concretamente que cuando el hombre y la mujer, por motivos serios, - como, por ejemplo, la educación de los hijos- no pueden cumplir la obligación de la separación, «asumen el compromiso de vivir en plena continencia, o sea de abstenerse de los actos propios de los esposos».

Del mismo modo el respeto debido al sacramento del matrimonio, a los mismos esposos y sus familiares, así como a la comunidad de los fieles, prohíbe a todo pastor - por cualquier motivo o pretexto incluso pastoral- efectuar ceremonias de cualquier tipo para los divorciados que vuelven a casarse. En efecto, tales ceremonias podrían dar la impresión de que se celebran nuevas nupcias sacramentalmente válidas y como consecuencia inducirían a error sobre la indisolubilidad del matrimonio válidamente contraído.

Actuando de este modo, la Iglesia profesa la propia fidelidad a Cristo y a su verdad; al mismo tiempo se comporta con espíritu materno hacia estos hijos suyos, especialmente hacia aquellos que inculpablemente han sido abandonados por su cónyuge legítimo.

La Iglesia está firmemente convencida de que también quienes se han alejado del mandato del Señor y viven en tal situación pueden obtener de Dios la gracia de la conversión y de la salvación si perseveran en la oración, en la penitencia y en la caridad".

Para comprender bien el discernimiento conviene hacer dos afirmaciones fundamentales: discernimiento no quiere decir discernir el estado de gracia de una persona; esto únicamente le corresponde a Dios. Como afirma el Concilio de Trento: "El juicio sobre el estado de gracia, obviamente corresponde solamente al interesado, tratándose de una valoración de conciencia"21. Santo Tomás de Aquino afirma la imposibilidad de juzgar el estado de gracia. El Concilio de Trento afirma además la imposibilidad de juzgar con certeza incluso el propio estado de gracia: "Nadie puede saber con certeza de fe, en la que no puede

${ }^{21}$ Juan Pablo II, Ecclesia de Eucharistia, n.37. 
caber error, que ha conseguido la gracia de Dios"22. Conviene recordar que el discernimiento es un vocablo con diferentes significados, y que implica siempre el lenguaje concreto de la encarnación ${ }^{23}$.

Es importante no tener conciencia de un pecado mortal no confesado. Es Dios el que juzga el corazón. La Iglesia siempre se ha limitado a juzgar la conducta externa o los estados objetivos de vida.

a) La praxis de no admitir a la Eucaristía a los divorciados vueltos a casar civilmente no corresponde al juicio según el cual viven en un estado de pecado mortal. Es un juicio sobre su estado de vida que está en contradicción objetiva con el misterio de la unión fiel entre Cristo y la Iglesia.

b) Un confesor es incapaz de discernir si las personas que son infieles al propio cónyuge de modo habitual y público viven en gracia de Dios. Por su misma naturaleza este tipo de juicio será siempre temerario y presuntuoso.

Si la Iglesia, exceptuando el juicio de un proceso de beatificación y canonización, no juzga el estado de gracia de una persona, sí que puede sin embargo juzgar el acto en sí mismo. Puede decir que si las personas realizan determinados tipos de acto (adulterio, homicidio, pedofilia...) con suficiente advertencia y un razonable grado de libertad, entonces este acto le hará perder la amistad con Dios. En otras palabras, cometen un pecado mortal. Esto es todo lo que los pastores tienen necesidad de saber y pueden saber. En definitiva, el sacerdote en el confesionario debe discernir el acto; el estado del alma le permanece oculto.

La "admisión" a los sacramentos tiene un significado público. Santo Tomás distingue entre pecadores ocultos y manifiestos. A los segundos, no se les debe dar la comunión, aunque la pidan. La cuestión de la admisión a la Eucaristía y a los demás sacramentos es un tema que tiene que ver con el estado de vida público y no con la conciencia privada de una persona. El matrimonio es esencialmente una realidad pública. La "mística" del sacramento tiene un carácter social.

En segundo lugar, discernimiento no quiere decir discernir las posibilidades concretas de la persona para adaptar a ellas la ley moral. El discernimiento debe producirse según la verdad y la enseñanza de la Iglesia, que afirma que siempre es posible observar los mandamiento de Dios, pues Dios mismo da la gracia para ello a quien se lo pide ${ }^{24}$.Para el neopelagianismo ${ }^{25}$, la ley no es expresión de la sabiduría de un Padre benévolo que nos invita a ser sus amigos. El Papa es justamente crítico hacia una "teología" moral moderna que ha olvidado que es

22 Cf. Concilio de Trento, DH 1534.

23 Cf. A.Diriart, “Discernement des esprits, discernement du corps",Anthropotes 31 (2015) 483-506.

24 Cf. Concilio de Trento, DH 1536.

25 Cf. Congregación para la Doctrina de la Fe, Carta Placuit Deo (22-02-2018). 
teología. Cristo nos da un corazón nuevo; su gracia es eficaz. Adaptar la ley moral a la percepción de nuestras capacidades no es una verdadera acción pastoral. Es una acción legal dirigida a hacer superflua la acción pastoral, que denota una falta de fe en Dios.La ley nace del amor que indica el camino hacia nuestra meta verdadera que es la comunión de amor con Dios.

AL 300 ofrece una definición elaborada de discernimiento. El objetivo del discernimiento consiste en ayudar a las personas a tomar conciencia de su situación delante de Dios, con las exigencias de verdad y caridad. El objetivo del discernimiento no es entonces encontrar excepciones, sino ayudar a aquellos que viven en una nueva unión a determinar los modos para vivir en la fidelidad a la promesa esponsal que hicieron a su cónyuge ante Dios y ante la Iglesia.

La modalidad y el estilo del discernimiento es pensar con la Iglesia. S. Ignacio de Loyola acuñó, en tal sentido, la expresión "pensar y sentir con la Iglesia". Por ello, discernir no significa justificar cualquier deseo concebible en ausencia de razones. Significa buscar las razones que responden a las exigencias de verdad y caridad.

El objeto del discernimiento es triple: el deseo, el vínculo matrimonial y los pasos concretos.

En el primer caso, el ejemplo paradigmático es la escena del encuentro de Jesús con la mujer samaritana (Jn 4). Discernir significa aquí preguntarse ¿Por qué deseo lo que deseo? ¿Qué es lo que deseo de verdad? ¿Cuál es el problema más profundo que me impide tener lo que deseo? El deseo de recibir la comunión no es derecho a recibirla. Este deseo puede derivar de un sentido de vergüenza en el momento de la comunión cuando todos se levantan a la llamada al altar. También pues estar basado en que aman al Señor en ambos casos con una catequesis adecuada se puede avanzar mucho.

El segundo objeto es discernir el vínculo matrimonial. Evidentemente no se trata de establecer un instrumento para que los divorciados vueltos a casar puedan acercarse a los sacramentos. Conviene advertir que una declaración de nulidad no es solución de nada, sino la indicación de un problema grave. No es un favor de la Iglesia, sino un juicio objetivo sobre la verdad de su matrimonio. Es mejor vivir en la verdad que en la mentira, aunque la verdad sea desagradable.

Finalmente se trata de discernir los pasos concretos a dar: en tal sentido, la primera pregunta es saber si la reconciliación es posible; otro paso posible es abandonar la unión extraconyugal; en tercer lugar, buscar los modos para vivir en abstinencia. La razón de esta práctica es el propio cónyuge legítimo.

El discernimiento consiste en encontrar modos para dirigir y acompañar a la personas a lo largo de un camino que tiene un destino. Se trata de la curación de la memoria. Las luces son fundamentalmente dos: la verdad del vínculo matrimonial y la verdad del deseo. Para todo este proceso de discernimiento se presupone el don y la luz de la fe. 


\section{CONCLUSIÓN}

Acompañar, discernir e integrar son los tres verbos que la exhortación elige para indicar el camino de la conversión pastoral. La Iglesia debe transmitir a los que se casan que se empeña en defender y luchar por su vínculo indisoluble en todo caso y en cualquier situación que se encuentren. La Iglesia reconoce que no dispone de un contexto social donde la visión evangélica pueda radicarse y madurar. Por ello es preciso trabajar por cambiar la cultura y generar un contexto favorable a la generación del sujeto cristiano. En todo caso, el horizonte en el que se mueve la esperanza cristiana lo describe de este modo la encíclicaVeritatis splendorn.103:

“El ámbito espiritual de la esperanza siempre está abierto al hombre, con la ayuda de la gracia divina y con la colaboración de la libertad humana.

Es en la cruz salvífica de Jesús, en el don del Espíritu Santo, en los sacramentos que brotan del costado traspasado del Redentor (cf. Jn 19,34), donde el creyente encuentra la gracia y la fuerza para observar siempre la ley santa de Dios, incluso en medio de las dificultades más graves. Como dice san Andrés de Creta, la ley misma «fue vivificada por la gracia y puesta a su servicio en una composición armónica y fecunda. Cada una de las dos conservó sus características sin alteraciones y confusiones. Sin embargo, la ley, que antes era un peso gravoso y una tiranía, se convirtió, por obra de Dios, en peso ligero y fuente de libertad».

Sólo en el misterio de la Redención de Cristo están las posibilidades «concretas» del hombre. «Sería un error gravísimo concluir... que la norma enseñada por la Iglesia es en sí misma un "ideal" que ha de ser luego adaptado, proporcionado, graduado a las — se dice- posibilidades concretas del hombre: según un "equilibrio de los varios bienes en cuestión". Pero, ¿cuáles son las "posibilidades concretas del hombre"? ¿Y de qué hombre se habla? ¿Del hombre dominado por la concupiscencia, o del redimido por Cristo? Porque se trata de esto: de la realidad de la redención de Cristo. ¡Cristo nos ha redimido! Esto significa que él nos ha dado la posibilidad de realizar toda la verdad de nuestro ser; ha liberado nuestra libertad del dominio de la concupiscencia.Y si el hombre redimido sigue pecando, esto no se debe a la imperfección del acto redentor de Cristo, sino a la voluntad del hombre de substraerse a la gracia que brota de ese acto. El mandamiento de Dios ciertamente está proporcionado a las capacidades del hombre: pero a las capacidades del hombre a quien se ha dado el Espíritu Santo; del hombre que, aunque caído en el pecado, puede obtener siempre el perdón y gozar de la presencia del Espíritu".

En este ámbito del misterio de la redención, la tarea principal de la Iglesia ha de ser la formación del sujeto cristiano capaz, por la gracia, de vivir la vocación al amor que proviene de Dios. Como afirma el Papa en la exhortación:"creer que somos buenos sólo porque «sentimos cosas» es un tremendo error" (AL 145). La conversión pastoral que desea la exhortación implica que el sujeto emotivo se transforme en un sujeto maduro. 